\title{
Property Changes of Woven Blouse Fabrics by bonding fusible interlinings for a 3D Virtual Try-on System
}

\author{
Myoung-Ok Kim and Myung-Ja Park ${ }^{\dagger}$ \\ Dept. of Fashion Stylist, Howon University; Gunsan, Korea \\ Dept. of Clothing and Textiles, Hanyang University; Seoul, Korea
}

\begin{abstract}
This study aims to analyze the changes in the mechanical properties of woven fabrics(cotton, linen, wool, silk, and polyester) by bonding fusible interlinings with varying deniers $(10 \mathrm{D}, 20 \mathrm{D}$, and 30D) for a 3D virtual try-on system(one that a user to try garments through screens using Avatar) developed over the last decade. We experimented with four mechanical properties and thicknesses of twenty-three specimens of interlining bonded fabrics including face fabrics and interlinings by using the KES-FB-AUTO system. The results showed that the tensile property increased(LT and RT increased and WT decreased) as the denier of the interlining increased; however, the change was slight. In contrast, the bending and shear properties increased significantly as the denier of the interlining increased on both the warp and the weft. This showed evidence that the interlining gives the fabrics size stability. The compression property was slight changed as the tensile property varies depending on the fibers and the denier of interlining. As expected, the thickness increased by bonding the interlining as the denier of interlining increased. From these results, we conclude that 3D users need to reflect these changes of woven fabrics by bonding interlinings when they try screen fittings to accurately express the fabric reality of manufactured garment.
\end{abstract}

Key words : woven fabric, mechanical properties, interlining, 3D virtual try-on system

\section{Introduction}

In the fashion textile industry, enhanced techniques have grown over the past two to three decades with the introduction of computer aided design(CAD) software. The 2D CAD system has become the main tool of the fashion industry replacing handmade skills. About a decade ago, the 3D virtual try-on system(giving one an opportunity to "try on" a garment on the computer screen before manufacturing or buying) was introduced as an offshoot of gaming. This novel animation system has been continually improved upon drawing considerable attention to it as a potential commercial possibility.

This 3D system has several commercial benefits that reduce the time and expense in garment development. A technical designer is able to adjust the fitting process by checking the garment on the screen before actually cutting the fabric(Kim \& Park, 2013). Also, this virtual system is used in online market using an avatar that represents the consumer's body image enabling the consumer to imagine "trying on" the garment before buying. In addition, younger generations, familiar with computer systems, prefer to try to buy garments over the Internet using this novel system.

$†$ Corresponding author; Myung-Ja Park

Tel. +82-2-2220-1192, Fax. +82-2-2297-1190

E-mail: mjapark@hanyang.ac.kr
There are many companies, for example, that offer 3D systems: V-Stitcher of Gerber, 3D Runway of OptiTex, 3DFit of Lectra, and CLO 3D of Virtual Fashion(Lee \& Shon, 2011). To generate a garment image on the screen, the 3D system uses the basic mechanical properties of fabrics in its default program. Every virtual system needs a numeric mechanical property for stiffness, bending ability, sheerness, density, thickness, and other properties(CLO 3D, 2013) to express a garment's images. A specific value range of mechanical properties differs depending on the systems. On the screen, the garment's image and fit should reflect the real manufacturing conditions for the modification or alteration of the pattern. Without these accurate mechanical properties, the screen altered pattern is not a real representation, but a fake animation.

In addition to, when the garments are manufactured, not only are the face fabrics used but also other materials such as interlinings, linings, elastic bands, and tapes etc. are used to enhance the garment's appearance, stability, and fit. An interlining is an additional layer of fabric inserted between the face fabric and the lining of the garment to give clothing a suitable appearance and stability(Kim et al., 2011). It was found that both the mechanical properties of the face fabric and that of the interlining were changed(Kim et al., 2011). By bonding the interlining onto the face fabric, the interlining is the most important factor that changes the mechanical properties. The change was not to be the simple sum of two property values but the way in which the mechanical property values 
Table 1. Physical properties of the woven face fabrics

\begin{tabular}{cccccc}
\hline Sample code & Fiber $(\%)$ & Fabric name & Fabric count $\left(\right.$ warp $\times$ weft $\left./ 5 \mathrm{~cm}^{2}\right)$ & Weight $\left(\mathrm{g} / \mathrm{m}^{2}\right)$ & Thickness $(\mathrm{mm})$ \\
\hline C & Cotton 100 & Twill & $232 \times 98$ & 186 & 0.392 \\
L & Linen 100 & Suiting & $76 \times 76$ & 18 & 0.446 \\
W & Wool 100 & Gabardine & $168 \times 120$ & 135 & 0.430 \\
S & Silk 100 & Natural noil & $114 \times 98$ & 198 & 0.563 \\
P & Polyester 100 & Duck & $98 \times 86$ & & 0.455 \\
\hline
\end{tabular}

increased or decreased. Also, time, pressure, and the type of interlining(fusible interlining or sew-on interlining) affects the change in properties of the face fabric.

Moreover, upon entering 21st century, with its well-being issues and demand for casual fashion trends, the fashion industry altered its marketing approach. The current fashion trend of light weight garments has brought commercial, light weight interlinings to the market. So, for example, current blouse garments are now manufactured using the current techniques of applying light weight interlinings.

So far, there have been studies on the mechanical properties of the face fabric with fusible interlining(Fan \& Ng, 2001; Kim et al., 2007; Seo \& Lee, 2003; Yun et al., 2009). Also, there have been studies on the $3 \mathrm{D}$ virtual try-on garment system how it reflects and works with the 3D system's actual garments (Choi \& Kim, 2012; Kang \& Lee, 2010; Uh, 2011). Also, there have been studies on the 3D visual " garment try on" system reflecting how the actual garments work using such a system. However, there is a lack of research for using the $3 \mathrm{D}$ virtual try-on system that well reflects the current fashion trend of the woven blouse garment that prefers a light weight interlining. Therefore, it is necessary to investigate property changes by bonding the interlinings on the woven face fabrics because the interlining is the most effected factor in property changes when the garments are manufactured. This study aims to analyze the degree of change of the mechanical properties after bonding the interlining on the face fabrics(cotton, linen, wool, silk, and polyester). Experimenting was done on the mechanical properties of tensile, bending, shear, and thickness because from analyzing the previous research(Choi \& Kim, 2012; Jee \& Rye, 1995) and from interviews with a 3D virtual try-on system company, these properties are the most essential for 3D system. It also will give the basic data that reflects the same mechanical properties as in real garment manufacturing by bonding the interlining for 3D users so that when a technical designer uses the 3D system, these mechanical property changes can be applied by bonding the interlinings onto the garments.

\section{Method}

\subsection{Material}

The researcher selected five kinds of face fabrics and three kinds of interlining for the experiment. The face fabrics were bought from Test Fabric, Inc.(USA). The face fabrics are cotton, linen, wool, silk, and polyester for blouse garments having weights of $135 \mathrm{~g}$ to $218 \mathrm{~g}$. The physical properties of the woven face fabrics are shown in Table 1. The interlinings were chosen by varying deniers(10D, 20D, and 30D), reflecting the current trend's use of light-weight interlining. We bought the commercial interlinings from Ilshin, Inc.(Korea). The physical properties of the interlinings are shown in Table 2. The specification of the combination of the

Table 2. Physical properties of the interlinings

\begin{tabular}{cccccccc}
\hline Sample code & Fiber $(\%)$ & Denier & Weight $\left(\mathrm{g} / \mathrm{m}^{2}\right)$ & Thickness $(\mathrm{mm})$ & Dot screen & Structure & Adhesive \\
\hline I-10 & Polyester 100 & 10 & 12 & 0.156 & 38 & Plain & Polyamide \\
I-20 & Polyester 100 & 20 & 23 & 0.186 & 35 & Plain & Polyamide \\
I-30 & Polyester 100 & 30 & 33 & 0.231 & 30 & Plain & Polyamide \\
\hline
\end{tabular}

Table 3. Specification of the combination of face fabrics and interlinings

\begin{tabular}{|c|c|c|c|c|}
\hline Fiber & Without interlining & 10 denier interlining & 20 denier interlining & 30 denier interlining \\
\hline Cotton & $\mathrm{C}-0$ & C-10 & $\mathrm{C}-20$ & $\mathrm{C}-30$ \\
\hline Linen & $\mathrm{L}-0$ & L-10 & L-20 & L-30 \\
\hline Wool & $\mathrm{W}-0$ & $\mathrm{~W}-10$ & $\mathrm{~W}-20$ & $\mathrm{~W}-30$ \\
\hline Silk & S-0 & S-10 & S-20 & S-30 \\
\hline Polyester & $\mathrm{P}-0$ & P-10 & P-20 & P-30 \\
\hline
\end{tabular}


face fabric and the interlining for the test are listed in Table 3, resulting in the preparation of twenty total specimens.

\subsection{Test method}

Woven-interlining bonded fabrics were made by combining the five types of face fabrics with three types of interlining, resulting in twenty specimens adding the non-bonded fabrics plus three interlinings, in total, twenty three specimens. We cut the fabric from a $10 \mathrm{~cm}$ edge; the sizes before we bonded the materials were warp 21 $\mathrm{cm}$, weft $21 \mathrm{~cm}$. We asked an expert who has manufactured garments for more than twenty years to fuse the face fabric with the interlining to perform the industrial standards. The expert bonded the materials according to the same directions(warp and weft) using an industrial steam iron(ES-94) in the same treatment conditions and manners as its everyday work; the fusing temperature of $120^{\circ} \mathrm{C}$ to $200^{\circ} \mathrm{C}$, the pressing time of 9 to 15 seconds, and the pressure of $3 \mathrm{kgf} / \mathrm{cm}^{2}$ to $4.5 \mathrm{kgf} / \mathrm{cm}^{2}$ corresponded to the recommendation manual from the interlining manufacturing company. After bonding the materials, we re-cut the material size(the warp $20 \mathrm{~cm}$, weft $20 \mathrm{~cm}$ ) to enter it into the Kawabata system. The mechanical properties such as tensile, bending, shear, compression, and thickness were tested by using the KES-FB-AUTO system(Kawabata Evaluation System for Fabric, Kato Tech. Co. Ltd, Japan). All specimens were treated under standard room conditions(temperature $20 \pm 1^{\circ} \mathrm{C}$, humidity $65 \pm 5 \% \mathrm{RH}$ ) for 24 hours. Every test was conducted three times and the average of the results was used for analysis.

\section{Results and Discussion}

\subsection{Tensile property}

The tensile property pertains to the property of the fabric tension when an external force is applied to the exterior of the fabric. By bonding the interlining on the woven fabric, the rate of change on the tensile property was slight than the researcher's expectation(Table 4).

Tensile linearity(LT) is related to the force and pressure of garments. If the value is small, it means that the fabric has good drape and comfort, and if the value is large, it means that the fabric's fatigue degree is great. Before bonding the interlining, the warp value was low in the order of linen, polyester, cotton, wool, and silk; and the order of the weft(linen, silk, wool, cotton, and polyester) was different. After bonding, the value changed slightly and the order of the low value was the same on both the warp and the weft. Overall, the LT was increased by bonding the interlining: the warp: 0.989 to 1.123 times, the weft: 0.964 to 1.039 times. The warp increased by bonding except in two cases; the weft in eight cases had decreased and in seven cases had increased depending on the fibers and the denier of the interlinings. In the case of interlinings only, LT of I-30 was increased. The rate of change was not larger than the researchers' expectations, even though the fabrics were bonded with the interlining. This result, we believe, is because the current interlining trend is using a light-weight, so there is only a slight affect on the fitting of garments.

Tensile energy(WT) is the correlation between a given power and a strength; if the value is small, the fabric is not easy to modify; if the value is large, it means that the fabric is easy to modify. Before bonding, the value on the warp was low in the order of cotton, polyester, linen, wool, and silk. The order was changed on the weft(polyester, linen, cotton, wool, and silk) because the value of the cotton differed significantly. After bonding, the order of the value remained the same on both the warp and the weft since the change was not significant. By bonding on the warp(0.720 to 1.068 times), WT was decreased except in three cases. On the weft( 0.929 to 1.053 times), two-thirds of the cases decreased or showed the same result as before bonding. Even though the rate of change was not significant, the result supports that the interlining used gives stability to the garments. We therefore believe that because the WT decreased, it supports the fact that the fabric is not easily modified.

Tensile resilience(RT) is the degree of recovery after tension. If a value is small, then a fabric has a good drape characteristic; if a value is large, it means that a fabric has meaningful size stability. Before bonding, the value was low on the warp in order of silk, linen, cotton, wool, and polyester; the order on the weft(cotton, silk, linen, wool, and polyester) was different. After bonding, on the warp, the order of the value changed; however, the weft order was the same as before bonding. Overall, the RT value on the warp(1.0 to 1.216 times) of the woven fabrics increased as the denier of the interlining increased. On the weft $(0.986$ to 1.088 times) the natural fabrics: cotton, linen, wool, and silk increased by bonding the interlining. However, the polyester-interlining bonded fabric decreased only slightly after bonding.

In summary, the values of LT, WT, and RT changed by bonding the interlining to the fabric, even though the rate of change for the woven-interlining bonded fabrics was minimal. The results of the tensile property are explained by numeric values supporting the use of garment interlining in manufacturing. The interlining gives garment size stability and a non- easily modified appearance. As a result of the above results, 3D users should be aware of the tensile changes after bonding the interlining so that the change of values upon the application of a garment's tensile property can be used.

\subsection{Bending property}

The bending property is a property that is related to the slip resis- 
Table 4. The rate of change of the tensile property of the woven-interlining bonded fabrics

\begin{tabular}{|c|c|c|c|c|c|c|c|c|c|c|c|c|}
\hline \multirow{2}{*}{$\begin{array}{c}\text { Sample } \\
\text { code }\end{array}$} & \multicolumn{4}{|c|}{ LT } & \multicolumn{4}{|c|}{ WT $\left(\mathrm{gf} \cdot \mathrm{cm} / \mathrm{cm}^{2}\right)$} & \multicolumn{4}{|c|}{ RT(\%) } \\
\hline & Warp & $\begin{array}{l}\text { Rate of } \\
\text { change }\end{array}$ & Weft & $\begin{array}{l}\text { Rate of } \\
\text { change }\end{array}$ & Warp & $\begin{array}{l}\text { Rate of } \\
\text { change }\end{array}$ & Weft & $\begin{array}{l}\text { Rate of } \\
\text { change }\end{array}$ & Warp & $\begin{array}{l}\text { Rate of } \\
\text { change }\end{array}$ & Weft & $\begin{array}{l}\text { Rate of } \\
\text { change }\end{array}$ \\
\hline $\mathrm{I}-10$ & 1.443 & & 1.067 & & 100.0 & & 84.50 & & 5.00 & & 3.08 & \\
\hline $\mathrm{I}-20$ & 1.718 & & 1.059 & & 100.0 & & 100.0 & & 12.30 & & 7.60 & \\
\hline $\mathrm{I}-30$ & 1.768 & & 1.209 & & 100.0 & & 100.0 & & 18.60 & & 16.35 & \\
\hline $\mathrm{C}-0$ & 1.224 & 1.000 & 1.361 & 1.000 & 4.10 & 1.000 & 11.30 & 1.000 & 70.73 & 1.000 & 50.00 & 1.000 \\
\hline $\mathrm{C}-10$ & 1.316 & 1.075 & 1.341 & 0.985 & 3.85 & 0.939 & 11.30 & 1.000 & 72.73 & 1.028 & 52.65 & 1.053 \\
\hline $\mathrm{C}-20$ & 1.323 & 1.081 & 1.312 & 0.964 & 4.10 & 1.000 & 11.05 & 0.978 & 70.73 & 1.000 & 54.75 & 1.095 \\
\hline $\mathrm{C}-30$ & 1.374 & 1.123 & 1.382 & 1.015 & 3.95 & 0.963 & 11.30 & 1.000 & 73.42 & 1.038 & 54.42 & 1.088 \\
\hline L-0 & 0.678 & 1.000 & 0.814 & 1.000 & 6.75 & 1.000 & 6.35 & 1.000 & 59.26 & 1.000 & 60.63 & 1.000 \\
\hline L-10 & 0.702 & 1.035 & 0.795 & 0.977 & 6.55 & 0.970 & 6.10 & 0.961 & 64.89 & 1.095 & 63.11 & 1.041 \\
\hline $\mathrm{L}-20$ & 0.690 & 1.018 & 0.85 & 1.044 & 6.35 & 0.941 & 5.90 & 0.929 & 66.93 & 1.129 & 64.41 & 1.062 \\
\hline $\mathrm{L}-30$ & 0.723 & 1.066 & 0.805 & 0.989 & 6.40 & 0.948 & 6.10 & 0.961 & 69.53 & 1.173 & 63.93 & 1.054 \\
\hline W-0 & 1.267 & 1.000 & 1.279 & 1.000 & 9.60 & 1.000 & 12.95 & 1.000 & 70.83 & 1.000 & 73.75 & 1.000 \\
\hline $\mathrm{W}-10$ & 1.313 & 1.036 & 1.254 & 0.980 & 10.50 & 1.094 & 12.10 & 0.934 & 70.95 & 1.002 & 77.69 & 1.053 \\
\hline $\mathrm{W}-20$ & 1.323 & 1.044 & 1.292 & 1.010 & 10.25 & 1.068 & 12.05 & 0.931 & 71.71 & 1.012 & 78.01 & 1.058 \\
\hline $\mathrm{W}-30$ & 1.351 & 1.066 & 1.29 & 1.009 & 8.75 & 0.911 & 12.45 & 0.961 & 71.43 & 1.008 & 76.71 & 1.040 \\
\hline S-0 & 1.276 & 1.000 & 1.125 & 1.000 & 13.40 & 1.000 & 15.25 & 1.000 & 54.10 & 1.000 & 56.72 & 1.000 \\
\hline S-10 & 1.360 & 1.066 & 1.163 & 1.034 & 13.70 & 1.022 & 15.90 & 1.043 & 58.03 & 1.073 & 58.81 & 1.037 \\
\hline S-20 & 1.262 & 0.989 & 1.102 & 0.980 & 12.40 & 0.925 & 14.80 & 0.970 & 62.10 & 1.148 & 60.81 & 1.072 \\
\hline S-30 & 1.340 & 1.050 & 1.169 & 1.039 & 9.65 & 0.720 & 15.40 & 1.010 & 65.80 & 1.216 & 59.09 & 1.042 \\
\hline P-0 & 1.067 & 1.000 & 1.380 & 1.000 & 5.20 & 1.000 & 4.75 & 1.000 & 74.04 & 1.000 & 82.11 & 1.000 \\
\hline P-10 & 1.149 & 1.077 & 1.389 & 1.007 & 5.20 & 1.000 & 5.00 & 1.053 & 74.04 & 1.000 & 81.00 & 0.986 \\
\hline P-20 & 1.159 & 1.086 & 1.366 & 0.990 & 5.10 & 0.981 & 4.85 & 1.021 & 74.51 & 1.006 & 81.44 & 0.992 \\
\hline P-30 & 1.180 & 1.106 & 1.347 & 0.976 & 5.25 & 1.010 & 4.85 & 1.021 & 75.24 & 1.016 & 81.44 & 0.992 \\
\hline
\end{tabular}

* Note: Among the specimens for each test, the light shaded columns indicate the lowest change rate and the dark shaded chambers indicate the highest change rate.

tance, drape characteristic, flexibility, and wrinkles or folds of the fabric. By bonding the interlining on the woven fabric, the rate of change on the bending property was significant(Table 5).

Bending rigidity(B), if the value is large, it means the fabric is stiff. Before bonding the interlining on the woven fabric, the value on the warp was low in order of the silk, wool, cotton, linen, and polyester. On the weft(silk, cotton, wool, polyester, and linen), the value differed, so there were differences between the warp and weft; especially, those of cotton had a significant difference. After bonding, the bending rigidity(B) increased in direct proportion to the increase of the denier of the interlining. This means that, as the bonded fabric becomes stiff, the denier of the interlining increases. The results are shown in Table 5. The rate of change varies on the $\operatorname{warp}(2.655$ to 4.245 times) more so than on the weft(1.246 to 3.288 times). On the warp, the wool-interlining bonded fabric showed the highest change rate, and polyester had the lowest change rate. On the weft, silk showed the highest change rate, and linen had the lowest.

The bending hysteresis(2HB) is similar to $\mathrm{B}$, so if the value is low, it means the fabric is flexible. Before bonding, the value of the warp was low in the order of wool, silk, polyester, linen, and cotton. On the weft, the order(wool, silk, cotton, polyester, and linen) differed. 2HB also had the big difference between the warp and the weft as in B. After bonding, the woven-interlining bonded fabric increased as the denier of the interlining increased, which means that the fabric was not flexible due to the interlining, a predicted result. The change rate also varied on the warp(2.19 to 4.974 times) more so than on the weft(1.246 to 2.641 times). On the warp, the wool-interlining bonded fabric had the highest change rate and the cotton-interlining had the lowest. On the weft, the silk-interlining bonded fabric had the highest change rate and linen the lowest.

From these results, we found that in both B and $2 \mathrm{HB}$, the rate of change of the wool-interlining bonded fabric was the highest on the warp, while the silk-interlining bonded fabric was the highest on 
Table 5. The rate of change of the bending property of the woven-interlining bonded fabrics

\begin{tabular}{|c|c|c|c|c|c|c|c|c|}
\hline \multirow{2}{*}{$\begin{array}{l}\text { Sample } \\
\text { code }\end{array}$} & \multicolumn{4}{|c|}{$\mathrm{B}\left(\mathrm{gf} \cdot \mathrm{cm}^{2} / \mathrm{cm}\right)$} & \multicolumn{4}{|c|}{$2 \mathrm{HB}\left(\mathrm{gf} \cdot \mathrm{cm}^{2} / \mathrm{cm}\right)$} \\
\hline & Warp & Rate of Change & Weft & Rate of Change & Warp & Rate of Change & Weft & Rate of Change \\
\hline $\mathrm{I}-10$ & 0.0037 & & 0.0027 & & 0.0086 & & 0.0079 & \\
\hline $\mathrm{I}-20$ & 0.0036 & & 0.0020 & & 0.0099 & & 0.0086 & \\
\hline $\mathrm{I}-30$ & 0.0079 & & 0.0057 & & 0.0115 & & 0.0099 & \\
\hline $\mathrm{C}-0$ & 0.449 & 1.000 & 0.0925 & 1.000 & 0.5308 & 1.000 & 0.0966 & 1.000 \\
\hline $\mathrm{C}-10$ & 0.5915 & 1.317 & 0.1408 & 1.522 & 0.5799 & 1.093 & 0.104 & 1.077 \\
\hline $\mathrm{C}-20$ & 0.8667 & 1.930 & 0.1215 & 1.314 & 0.6972 & 1.313 & 0.1006 & 1.041 \\
\hline $\mathrm{C}-30$ & 1.7393 & 3.874 & 0.1798 & 1.944 & 1.1625 & 2.190 & 0.1324 & 1.371 \\
\hline L-0 & 0.4832 & 1.000 & 0.9926 & 1.000 & 0.3846 & 1.000 & 0.7323 & 1.000 \\
\hline L-10 & 0.732 & 1.515 & 1.1292 & 1.138 & 0.4943 & 1.285 & 0.8622 & 1.177 \\
\hline L-20 & 1.0238 & 2.119 & 1.1985 & 1.207 & 0.6805 & 1.769 & 0.8737 & 1.193 \\
\hline L-30 & 1.4914 & 3.087 & 1.2542 & 1.264 & 1.0914 & 2.838 & 0.9123 & 1.246 \\
\hline $\mathrm{W}-0$ & 0.1745 & 1.000 & 0.1211 & 1.000 & 0.0534 & 1.000 & 0.0389 & 1.000 \\
\hline $\mathrm{W}-10$ & 0.346 & 1.983 & 0.1984 & 1.638 & 0.1076 & 2.015 & 0.0621 & 1.596 \\
\hline $\mathrm{W}-20$ & 0.4707 & 2.697 & 0.2111 & 1.743 & 0.1409 & 2.639 & 0.0694 & 1.784 \\
\hline W-30 & 0.7408 & 4.245 & 0.2609 & 2.154 & 0.2656 & 4.974 & 0.0907 & 2.332 \\
\hline S-0 & 0.133 & 1.000 & 0.0688 & 1.000 & 0.0802 & 1.000 & 0.0459 & 1.000 \\
\hline S-10 & 0.3697 & 2.780 & 0.1977 & 2.874 & 0.175 & 2.182 & 0.0964 & 2.100 \\
\hline S-20 & 0.4202 & 3.159 & 0.1777 & 2.583 & 0.1862 & 2.322 & 0.0924 & 2.013 \\
\hline S-30 & 0.4885 & 3.673 & 0.2262 & 3.288 & 0.2906 & 3.623 & 0.1212 & 2.641 \\
\hline P-0 & 0.8238 & 1.000 & 0.8550 & 1.000 & 0.3055 & 1.000 & 0.3653 & 1.000 \\
\hline P-10 & 1.6309 & 1.980 & 1.4494 & 1.695 & 0.742 & 2.429 & 0.6374 & 1.745 \\
\hline P-20 & 1.3947 & 1.693 & 1.2737 & 1.490 & 0.6225 & 2.038 & 0.5628 & 1.541 \\
\hline P-30 & 2.1875 & 2.655 & 1.2191 & 1.426 & 1.0536 & 3.449 & 0.5251 & 1.437 \\
\hline
\end{tabular}

* Note: Among the specimens for each test, the light shaded columns indicate the lowest change rate and the dark shaded chambers indicate the highest change rate.

the weft, and the linen-interlining bonded fabric had the lowest change rate on the weft. The result of the change in the bending property was largest on the warp than on the weft. The interesting result was on the polyester; the bending properties increased after bonding; however, the rate of change slightly decreased as the denier of the interlining increased. It is therefore deemed necessary to do further research to more clearly explain these results. It was obvious that the bending property had changed after bonding the interlining, so that the 3D users need to apply these changes to express the reality of fabric of garments.

\subsection{Shear property}

Shear property is the property that is related to the appearance of garment, drape, and fitting; It is closely related with the bending property. By bonding the interlining on the woven fabric, the rate of change on the shear property varies according to the fabrics(Table 6).

Shear rigidity $(\mathrm{G})$, if a value is large, gives garment shape stability. Before bonding, the value in both the warp and weft was low in the order of linen, wool, silk, cotton, and polyester. After bonding, the $\mathrm{G}$ increased as the interlining thickness increased. The result is similar to the bending property, supporting the fact that the interlining bonded fabric improved the garment shape stability. The rate of change varied on the warp(1.457 to 3.359 times) more so than on the weft(1.174 to 3.455 times). On the warp, the lineninterlining bonded fabric had the highest change, while the silkinterlining bonded fabric had the lowest. On the weft, the lineninterlining bonded fabric also had the highest change rate, while the polyester- interlining bonded fabric had the lowest.

Shear hysteresis(2HG), if a value is large, the fabric becomes more rigid rather than flexible. Before bonding, the value in both on the warp and weft was low in the order of linen, wool, silk, polyester, and cotton. After bonding, the order changed because the value of the linen-interlining bonded fabric significantly changed on the warp(12.765 times) and on the weft(29.667 times). The change rate also varied on the weft(1.969 to 29.667 times) more than on the warp( 0.875 to 12.765 times). On the warp, the linen- 
Table 6. The rate of change of the shear property of the woven-interlining bonded fabrics

\begin{tabular}{|c|c|c|c|c|c|c|c|c|}
\hline \multirow{2}{*}{$\begin{array}{l}\text { Sample } \\
\text { code }\end{array}$} & \multicolumn{4}{|c|}{$\mathrm{G}(\mathrm{gf} / \mathrm{cm} \cdot \mathrm{deg})$} & \multicolumn{4}{|c|}{$2 \mathrm{HG}(\mathrm{gf} / \mathrm{cm})$} \\
\hline & Warp & Rate of Change & Weft & Rate of Change & Warp & Rate of Change & Weft & Rate of Change \\
\hline I-10 & 0.26 & & 0.22 & & 0.10 & & 0.10 & \\
\hline $\mathrm{I}-20$ & 0.24 & & 0.23 & & 0.20 & & 0.17 & \\
\hline $\mathrm{I}-30$ & 0.31 & & 0.32 & & 0.30 & & 0.38 & \\
\hline $\mathrm{C}-0$ & 1.51 & 1.000 & 1.43 & 1.000 & 2.42 & 1.000 & 2.25 & 1.000 \\
\hline $\mathrm{C}-10$ & 1.75 & 1.159 & 1.61 & 1.126 & 3.3 & 1.364 & 2.72 & 1.209 \\
\hline $\mathrm{C}-20$ & 2.40 & 1.589 & 2.12 & 1.483 & 4.65 & 1.921 & 3.97 & 1.764 \\
\hline $\mathrm{C}-30$ & 2.74 & 1.815 & 2.60 & 1.818 & 4.38 & 1.810 & 4.43 & 1.969 \\
\hline L-0 & 0.78 & 1.000 & 0.77 & 1.000 & 0.17 & 1.000 & 0.09 & 1.000 \\
\hline L-10 & 1.12 & 1.436 & 1.15 & 1.494 & 0.68 & 4.000 & 0.73 & 8.111 \\
\hline L-20 & 1.84 & 2.359 & 1.72 & 2.234 & 0.8 & 4.706 & 1.23 & 13.667 \\
\hline L-30 & 2.62 & 3.359 & 2.66 & 3.455 & 2.17 & 12.765 & 2.67 & 29.667 \\
\hline W-0 & 0.93 & 1.000 & 0.82 & 1.000 & 0.50 & 1.000 & 0.40 & 1.000 \\
\hline $\mathrm{W}-10$ & 1.14 & 1.226 & 1.04 & 1.268 & 0.57 & 1.140 & 0.57 & 1.425 \\
\hline $\mathrm{W}-20$ & 1.59 & 1.710 & 1.39 & 1.695 & 1.2 & 2.400 & 0.95 & 2.375 \\
\hline W-30 & 1.72 & 1.849 & 1.65 & 2.012 & 0.98 & 1.960 & 1.25 & 3.125 \\
\hline S-0 & 1.40 & 1.000 & 1.22 & 1.000 & 0.65 & 1.000 & 0.55 & 1.000 \\
\hline S-10 & 1.78 & 1.271 & 1.52 & 1.246 & 0.77 & 1.185 & 0.73 & 1.327 \\
\hline S-20 & 1.59 & 1.136 & 1.43 & 1.172 & 0.88 & 1.354 & 0.82 & 1.491 \\
\hline S-30 & 2.04 & 1.457 & 1.91 & 1.566 & 0.77 & 1.185 & 1.25 & 2.273 \\
\hline $\mathrm{P}-0$ & 4.30 & 1.000 & 6.05 & 1.000 & 1.60 & 1.000 & 0.60 & 1.000 \\
\hline P-10 & 5.85 & 1.360 & 4.40 & 0.727 & 1.30 & 0.813 & 0.60 & 1.000 \\
\hline P-20 & 6.35 & 1.477 & 5.80 & 0.959 & 2.20 & 1.375 & 1.60 & 2.667 \\
\hline P-30 & 7.15 & 1.663 & 7.10 & 1.174 & 1.40 & 0.875 & 1.70 & 2.833 \\
\hline
\end{tabular}

* Note: Among the specimens for each test, the light shaded columns indicate the lowest change rate and the dark shaded chambers indicate the highest change rate.

interlining bonded fabric had the highest change rate and the polyester-interlining bonded fabric had the lowest; even the $2 \mathrm{HG}$ value decreased by bonding. On the weft, the linen-interlining bonded fabric had the highest change rate, while the cotton-interlining bonded fabric had the lowest.

With these results, we found that, in both $\mathrm{G}$ and $2 \mathrm{HG}$, on the warp and on the weft, the linen-interlining bonded fabric had the highest rate of change. This resulted because the linen fiber is easily wrinkled and has low elastic recovery because of the hydrogen bond; however, the polyester interlining helps crease resistance. The silk-interlining bonded fabric on the warp in $\mathrm{G}$ had the lowest change rate, while the cotton-interlining bonded fabric on the weft in $2 \mathrm{HG}$ had the lowest change. The result of the change of the shear property was larger on the weft rather than on the warp. With the polyester, on the weft in G, the shear property decreased after bonding the interlining with $10 \mathrm{D}$ and $20 \mathrm{D}$, while the $30 \mathrm{D}$ bonding increased slightly. As we surmised, this result is because polyester, a synthetic fiber, becomes more flexible with the heat application during the bonding process. Therefore, the $3 \mathrm{D}$ user needs to be aware of these changes especially with the linen-interlining bonded fabric because of its significant change.

\subsection{Compression property}

The compression property is the value that is related to the fullness, fineness, voluptuousness(or plumpness). Such values are associated with the thickness of the fabric. The results of the woven-interlining bonded fabric are listed in Table 6. By bonding the interlining on the woven fabric, the compression property was changed slightly according to the woven fabric.

Linearity(LC) is the property of having only one dimension to the compression. If the value is low, the compression is easy. Before bonding, the value was low in the order of linen, cotton, polyester, wool, and silk. The order was changed by interlining. After bonding, the order was linen, cotton, wool, silk, and polyester since the polyester-interlining bonded fabric was highly changed, and the linen-interlining bonded fabric was the lowest, even the 
linen-interlining on the 30 denier interlining was slightly decreased in contrast to most of the woven-interlining bonded fabric, which was slightly increased. Also, it shows the various change rates according to the denier of the interlining. The silk and polyester were increased as the denier of the interlining increased. However, the cotton, linen, and wool slightly decreased as the denier of the interlining increased. We believe that the silk and polyester are the filament fabrics which are already compacted, so it was not easy to compact.

In the compression energy(WC), if the value is low, this means that the energy for compression needs less energy. Before bonding, the value was low in the order of polyester, wool, silk, linen, and cotton. This order changed because of the interlining since this value had decreased slightly and changed into a descending(cotton, silk) or ascending order(linen, wool, and polyester). After bonding the interlining, the linen-interlining bonded fabric had the highest change rate. The cotton-interlining and silk-interlining decreased as the denier of the interlining increased. The polyester-interlining and wool-interlining slightly increased by bonding.
Compression resilience $(\mathrm{RC})$ is elastic recovery. If the value is high, it means that the fabric is flexible with regards to the compression. Before bonding, the value was low in the order of cotton, linen, wool, silk, and polyester. After bonding, overall, the value of most of the woven-interlining bonded fabric increased by interlining. The rate of change was slight. The cotton-interlining and silkinterlining increased as the denier of the interlining increased. However, the silk-interlining decreased. Using bonding, the 20 denier interlining of the silk, and the 10 denier and 20 denier of the polyester decreased. Further study is necessary to clearly examine the relationship between the denier of the interlining and the fibers using larger specimens.

From these results, by bonding the interlining on the fabrics, overall, it was not easy to compress the fabric, so that it needs more energy than before the bonding. Also, the recovery improved by interlining, an end result of using interlining. However, there were opposite results with the use of specific fibers and the various deniers of the interlining. Therefore, a 3D user must apply real changes by interlining because the change of the compression

Table 7. The rate of change of the compression property of the woven-interlining bonded fabrics

\begin{tabular}{|c|c|c|c|c|c|c|c|}
\hline Sample code & $\overline{\mathrm{LC}}$ & Rate of Change & $\overline{\mathrm{WC}}$ & $\left(\mathrm{gf} \cdot \mathrm{cm} / \mathrm{cm}^{2}\right)$ & Rate of Change & RC (\%) & Rate of Change \\
\hline $\mathrm{I}-10$ & 0.603 & & & 0.069 & & 8.24 & \\
\hline $\mathrm{I}-20$ & 0.518 & & & 0.074 & & 21.51 & \\
\hline $\mathrm{I}-30$ & 0.552 & & & 0.097 & & 41.07 & \\
\hline $\mathrm{C}-0$ & 0.243 & 1.000 & & 0.235 & 1.000 & 31.25 & 1.000 \\
\hline C-10 & 0.327 & 1.346 & & 0.194 & 0.826 & 35.17 & 1.125 \\
\hline $\mathrm{C}-20$ & 0.317 & 1.305 & & 0.169 & 0.719 & 35.13 & 1.124 \\
\hline $\mathrm{C}-30$ & 0.305 & 1.255 & & 0.163 & 0.694 & 36.57 & 1.170 \\
\hline L-0 & 0.232 & 1.000 & & 0.128 & 1.000 & 36.99 & 1.000 \\
\hline L-10 & 0.297 & 1.280 & & 0.148 & 1.156 & 41.98 & 1.135 \\
\hline L-20 & 0.238 & 1.026 & & 0.179 & 1.398 & 45.13 & 1.220 \\
\hline L-30 & 0.208 & 0.897 & & 0.168 & 1.313 & 45.6 & 1.233 \\
\hline W-0 & 0.338 & 1.000 & & 0.126 & 1.000 & 48.62 & 1.000 \\
\hline $\mathrm{W}-10$ & 0.388 & 1.148 & & 0.128 & 1.016 & 52.66 & 1.083 \\
\hline $\mathrm{W}-20$ & 0.380 & 1.124 & & 0.129 & 1.024 & 44.25 & 0.910 \\
\hline $\mathrm{W}-30$ & 0.350 & 1.036 & & 0.135 & 1.071 & 51.52 & 1.060 \\
\hline S-0 & 0.406 & 1.000 & & 0.231 & 1.000 & 49.09 & 1.000 \\
\hline S-10 & 0.420 & 1.034 & & 0.209 & 0.905 & 60.24 & 1.227 \\
\hline S-20 & 0.428 & 1.054 & & 0.219 & 0.948 & 56.41 & 1.149 \\
\hline S-30 & 0.454 & 1.118 & & 0.202 & 0.874 & 55.70 & 1.135 \\
\hline P-0 & 0.311 & 1.000 & & 0.087 & 1.000 & 50.47 & 1.000 \\
\hline P-10 & 0.382 & 1.228 & & 0.100 & 1.149 & 47.78 & 0.947 \\
\hline P-20 & 0.397 & 1.277 & & 0.100 & 1.149 & 39.56 & 0.784 \\
\hline P-30 & 0.442 & 1.421 & & 0.096 & 1.103 & 53.48 & 1.060 \\
\hline
\end{tabular}

* Note: Among the specimens for each test, the light shaded columns indicate the lowest change rate and the dark shaded chambers indicate the highest change rate. 
property varies according to the fibers and the denier of the interlining.

\subsection{Thickness}

The thickness of the woven-interlining bonded fabric changed after bonding the face fabrics as shown in Table 8. Before bonding, the thickness was thinnest in the order of cotton, wool, linen, polyester, and silk. After bonding, the thickness of the woven-interlining bonded fabric changed to cotton, wool, polyester, linen, and silk. The thickness increased as we expected(1.082 to 1.306 times). However, the change rate differed according to the type of fibers and fabric name which was as interesting result. The thickness of the bonded fabrics was not just the sum of the face fabric plus that of the interlining because when the fabric was bonded by heat and pressure, the structure was flat and compressed. As explained in the previous research(Choi \& Kim, 2012), the thickness of the fabric was flattened and compressed when the adhesive agent of the interlining was fusing it. Therefore, the distance within the fiber is closer than without the interlining, and also the crimp was flattened. The time and pressure affects the thickness of the interliningbonded fabrics(Kim \& Song, 2001). For clarity, further study is

Table 8. The rate of change of the thickness of the woven- interlining bonded fabrics

\begin{tabular}{|c|c|c|}
\hline Sample code & Thickness(mm) & Rate of change \\
\hline $\mathrm{C}-0$ & 0.392 & 1.000 \\
\hline C-10 & 0.438 & 1.117 \\
\hline C-20 & 0.466 & 1.187 \\
\hline C-30 & 0.497 & 1.267 \\
\hline L-0 & 0.446 & 1.000 \\
\hline L-10 & 0.515 & 1.155 \\
\hline L-20 & 0.550 & 1.233 \\
\hline L-30 & 0.570 & 1.278 \\
\hline W-0 & 0.430 & 1.000 \\
\hline W-10 & 0.502 & 1.168 \\
\hline $\mathrm{W}-20$ & 0.540 & 1.255 \\
\hline $\mathrm{W}-30$ & 0.561 & 1.306 \\
\hline S-0 & 0.563 & 1.000 \\
\hline S-10 & 0.609 & 1.082 \\
\hline S-20 & 0.657 & 1.167 \\
\hline S-30 & 0.677 & 1.202 \\
\hline P-0 & 0.455 & 1.000 \\
\hline P-10 & 0.517 & 1.136 \\
\hline P-20 & 0.536 & 1.178 \\
\hline P-30 & 0.564 & 1.239 \\
\hline
\end{tabular}

* Note: Among the specimens for each test, the light shaded columns indicate the lowest change rate and the dark shaded chambers indicate the highest change rate. suggested to examine how the pressure methods, time, and pressure affects the thickness of the bonded fabric.

\section{Conclusion}

This study examined the change rate for the mechanical properties of woven fabrics by bonding the interlinings. The data from this study gives $3 \mathrm{D}$ users a property change information base from which to work when bonding interlining to woven fabrics where a difference in the mechanical properties depends on the fibers and the interlining deniers. What we found from this research is as follows.

The rate of change in the tensile property was slight by bonding the interlining on the woven fabrics. However, the bending property and shear property changed significantly by bonding the interlining. It showed evidence that the interlining gives the fabrics size stability; In particular, the linen-interlining bonded fabric, which had the highest change rate among the woven fabrics. Also, the change was different from the warp and weft depending on the fibers. Therefore, we conclude that it is necessary for 3D users to pay attention to these changes. They need to apply the numeric properties differently on the warp and weft when generating the garment that are manufactured with the interlining underneath of the face fabric. The change of the compression property was slight as the tensile property varies depending on the fibers and the denier of interlining. In addition, the thickness changed by bonding the interlining; the fabrics became thicker as the denier of interlining increased.

These rates of changes results from the bonding of interlining are useful and practical for 3D users to reflect the actual properties of the fabric when they express the garment. However, there is still a gap between the numeric value from the KES-FB-AUTO system and the values that are used in the various 3D systems in companies. If the users of the $3 \mathrm{D}$ system programs are able to use the KES-FB-AUTO system results directly, the results of 3D garment manufacturing would reflect an actual, precise manufacturing process. Therefore, further investigations for applying these numeric results on the 3D system are required. Also, research on knit fabrics is suggested. Because these data showed the relationship between the yarn diameter of interlinings and the properties of bonded fabrics, it could be estimated the changes of the bonded-fabric properties without KES experimental analysation.

\section{References}

Choi, K. M., \& Kim, J. G. (2012). A study on the tensile deformation characteristics of knits and appearance using 3D digital virtual clothing systems. Journal of Fashion Business, 16(2), 151-162. 
CLO 3D. (2013). Marvelous Designer Manual version 3.70. Seoul: Author.

Fan, J., \& Ng, Y. N. (2001). Objective evaluation of the hand of nonwoven fusible interlining. Textile Research Journal, 71(8), 661-666.

Jee, J. W., \& Rye, H. S. (1995). Changes of mechanical properties of wool fabrics with fusible interlinings. Journal of the Korean Society of Clothing and Textiles, 19(4), 671-683.

Kang, I. Y., \& Lee, S. Y. (2010). A study on the shape of shirring using 3D virtual clothing system. Journal of the Korean Society of Clothing and Textiles, 34(7), 1111-1125.

Kim, I. Y., Oh, S. M., \& Song, W. S. (2007). The correlation analysis between the appearance-related performances and the mechanical properties on lyocell-interlining bonded fabric. Fibers and Polymers, 8(3), 326-329.

Kim, I. Y., \& Song, W. S. (2001). The effect of fusible interlining on the appearance related properties and mechanical characteristics for the lyocell fabric (part I). Journal of the Korean Society of Clothing and Textiles, 25(7), 1193-1202.

Kim, K. O., Inui, S., \& Takatera, M. (2011). Verification of prediction for bending rigidity of woven fabric laminated with interlining by adhesive bonding. Textile Research Journal, 81(6), 598- 607.

Kim, M. O., \& Park, M. J. (2013). Effects of fusible interlinings on mechanical properties and hand of cotton fabrics for jackets. Journal of the Korean Fiber Society, 50(6), 351-358. doi:/ 10.12772/TSE.2013.50.351.

Lee, M. J., \& Shon, H. S. (2011). A study on the application of 3D apparel CAD system to the domestic and overseas fashion education. Journal of the Korean Society and Textiles, 35(9), 11121124.

Seo, M. H., \& Lee, S. Y. (2003). Effect of interlining adhesion on the bending behavior of wool fabrics. Journal of the Korean Fiber Society, 40(3), 238-249.

Uh, M. K. (2011). Development of a pattern and visual image for a one-piece dress using a 3D virtual clothing system. The Research Journal of the Costume Culture, 19(3), 597-611.

Yun, S. Y., Kim, S., and Park, C. K. (2009). Development of an expert system for optimum fusible interlining. Fashion and Textile Journal, 11(4), 648-660.

(Received 23 September 2014; 1st Revised 20 October 2014; 2nd Revised 10 November 2014; Accepted 29 November 2014)

Copyright (C) 2014 (by) the authors. This article is an open access article distributed under the terms and conditions of the Creative Commons Attribution license (http://creativecommons.org/licenses/by/3.0/), which permits unrestricted use, distribution, and reproduction in any medium, provided the original work is properly cited. 